\title{
Artelogie
}

Recherche sur les arts, le patrimoine et la littérature de l'Amérique latine

$17 \mid 2021$

Transformaciones en Cuba contemporánea: cultura y sociedad

\section{Transformaciones en Cuba contemporánea: cultura y sociedad}

Iván César Morales Flores y Odette Casamayor-Cisnero

\section{OpenEdition}

\section{Journals}

Edición electrónica

URL: https://journals.openedition.org/artelogie/9865

DOI: $10.4000 /$ artelogie.9865

ISSN: 2115-6395

Editor

Association ESCAL

Referencia electrónica

Iván César Morales Flores y Odette Casamayor-Cisnero, «Transformaciones en Cuba contemporánea: cultura y sociedad», Artelogie [En línea], 17 | 2021, Publicado el 27 septiembre 2021, consultado el 15 septiembre 2022. URL: http://journals.openedition.org/artelogie/9865 ; DOI: https://doi.org/10.4000/ artelogie.9865

Este documento fue generado automáticamente el 15 septiembre 2022.

All rights reserved 


\title{
Transformaciones en Cuba contemporánea: cultura y sociedad
}

\author{
Iván César Morales Flores y Odette Casamayor-Cisnero
}

1 El colapso del sistema socialista en Europa del Este en el ocaso del siglo XX y la crisis económica que acarrearía para los cubanos; el devastador "Período especial en tiempos de paz"; las sucesivas oleadas migratorias a Estados Unidos y la expansión global de la diáspora; las reformas económicas y constitucionales, y el ahondamiento de las desigualdades socioeconómicas, raciales, de género y sexuales, han impactado inexorablemente la producción cultural cubana del presente siglo.

2 Este número de Artelogie propone examinar el quehacer cultural contemporáneo de la nación caribeña a través del análisis y la reflexión innovadora propuestos por cuatro autoras, cuyos enfoques interdisciplinarios e interseccionales exploran problemáticas fluctuantes entre continuidad y ruptura, el pasado, el presente y la imaginación de posibles futuros, lo local y lo global, subjetividades y transterritorialidad en la música, la literatura y las artes visuales creadas por cubanos dentro y fuera de la isla. Las cuatro contribuciones que aquí se incluyen convidan al lector a profundizar, desde el entreverado campo cultural, en el conocimiento de las más acuciantes dinámicas que agitan la sociedad cubana, sus avatares, sus claroscuros y entresijos. Diseñan un mapa cargado de incógnitas que, en su siempre ambigua expansión-contención, surca nuevos e inexcusables desafíos a los estudios de la cambiante realidad sociocultural cubana.

Desde el ámbito de los estudios de género, sexualidad y racialización este número ofrece un valioso texto de Mabel Cuesta (Krudxs Cubensi: cuerpo y perfomance para derribar fronteras) que nos adentra con avidez en el necesario universo de los estudios socioculturales y, como consecuencia, musicales de la Cuba actual y su diáspora. La lectura que aquí se hace de la trayectoria y la producción experimental de Krudxs Cubensi, dúo de hip hop emigrado a Estados Unidos en 2006, revela un multifacético diálogo entre el auto-reconocimiento de sus integrantes como "sujetxs" no binarios, su 
condición como artista y activistas, a la vanguardia del hip hop afrolatino, y su lucha contra el imaginario patriarcal, heteronormativo, la marginalidad de los sujetos LGBTIQ, la política cubana actual y los poderes hegemónicos globales. Cuerpos, performances, escenas, políticas sociales, identidades, géneros y sonidos se congregan en un texto de especial relieve y apertura de posicionamientos frente a la realidad cubana del presente siglo.

Damaris Puñales Alpízar expone, por su parte, un contrapunteo sugerente y revelador entre dos obras del oscuro universo de la represión literaria en la órbita socialista de la extinta URSS y la Cuba de las últimas décadas, publicados en España en el año 2007. La primera de ellas, sobre los archivos literarios de la KGB, Crimen sin castigo, de Vitali Shentalinski; la segunda, La fiesta vigilada, de Antonio José Ponte. Su texto (Los archivos de la censura: represión literaria en la Unión Soviética y en Cuba) brinda una contribución de alto nivel e interés para el conocimiento profundo del contexto cultural cubano postrevolucionario y actual, a partir de una premisa que encierra la complejidad y fascinación de su alcance: la imposibilidad de saber a ciencia cierta si existen en la Cuba del siglo XXI archivos que den fe de esa literatura prohibida y sus autores, del mismo modo en que ha ocurrido en la antigua Unión de Repúblicas Socialistas Soviéticas.

Hombres negros que en silencio miran a cámara: Agencia afrodescendiente, descolonización y representación de masculinidades en pugna en el vídeo cubano (1997-2014) es el texto que propone Suset Sánchez Sánchez a través de un exquisito análisis de piezas de videoarte de jóvenes artistas cubanos (Carlos Garaicoa, Juan Carlos Alom, Alexandre Arrechea, Raychel Carrión y el colectivo Los Carpinteros). Su contribución ahonda en las problemáticas del contexto racial y cultural de la isla, con un interés punzante en la resignificación del cuerpo afrodescendiente, en tanto signo de resistencia, pluralidad, orgullo y diferencia, frente a los subterfugios raciales de la sociedad cubana actual (los imaginarios populares) y la narrativa política oficial (las prácticas institucionales). Sánchez dirige su atención a esos silencios protagonistas de narraciones audiovisuales que, en sus performances, claman mensajes de racismo, marginalidad y colonialidad en pleno siglo XXI.

El artículo de Cecilia González Godino (Aproximaciones epidérmicas al contexto caribeño: una poética de lo epidérmico en "Maleficio", de Marta María Pérez Bravo) nos sumerge, por último, en las tramas liminales de las identidades caribeñas, a través de una artista cubana contemporánea cuya obra fotográfica interpela el desarraigo del sujeto colonizado y el ritual antillano. Enmarcada dentro de la denominada «fotografía del Período Especial», Maleficio centra su discurso en el reconocimiento de la memoria y las subjetividades culturales del sujeto cubano y caribeño, y no en las pretéritas narrativas revolucionarias, épicas y heroicas de la isla. La piel, en tanto órgano biológico y simbólico de análisis, proporciona a la autora de este texto un punto de vista de excepcional elasticidad de fronteras y márgenes periféricos, para vislumbrar «otros» espacios de transferencia, de representación y de agencia, desde una aproximación epidérmica y fractal de lo dinámico y lo caótico del acontecer cultural caribeño.

7 La sección de entrevista de este número se ha dedicado, a modo de homenaje, a una de las figuras más controvertidas y notorias de la musicología cubana de los últimos tiempos: Danilo Orozco (1944-2013). Su título (¿Musicología mundial en chancleta de palo?) metaforiza el alcance internacional y el fundamento esencial de la obra de este excepcional estudioso de procesos socio-musicales de Cuba, el Caribe y las Américas. A través de esta entrevista, publicada originalmente en La Gaceta de Cuba (2004), la 
musicóloga Miviam Ruiz desenreda los hilos de la sólida formación científica y musical de esta figura; de sus profundos vínculos con el entorno cultural cubano y de su fértil y experimental labor académica. Lo conceptual e histórico sustentan reflexiones sobre las proyecciones del son cubano, las categorías de género y estilo en música, así como la enseñanza y la investigación musicológicas. "Chancleta de palo" es una frase contextual que remite a tradiciones musicales raigales del oriente de Cuba, tan cercano a la actividad científica de Orozco, a la vez que hace alegoría de un proceder musicológico de la isla que el entrevistado analiza y critica con su típico lenguaje, ora caústico, ora jocoso, pero siempre filosófico y comprometido.

8 Abre este número especial de Artelogie amplias ventanas sobre la producción cultural cubana, posibilitando de la suerte una comprensión aguda de la vida y los imaginarios hoy circulando entre cubanos dentro y fuera de la isla. Los ensayos aquí reunidos desbordan empero la exclusiva revisión de la experiencia artística, volcándose sobre álgidas problemáticas sociopolíticas, ideológicas y éticas. Con agudeza crítica, sus autoras desvelan diversos espacios de la existencia cubana, por lo general sumidos en la oscuridad que han propiciado décadas de desinformación sobre la realidad nacional. Pues persiste un vacío informacional en torno a la isla, que es desafortunadamente colmado por la siempre inexacta y desvirtuadora propaganda política, lanzada desde la derecha tanto como de la izquierda; mientras, permanece sumido en la incomprensión el pueblo de Cuba: sin voz ni audiencia, su experiencia desfigurada bajo mal zurcidos engendros retóricos.

9 Contra esa incomprensión, resistiendo la avalancha propagandística y descorriendo telones sobre la realidad de los cubanos, irrumpen estos ensayos, cuya iluminadora precisión y arte delicado agradecerán sin dudas los lectores.

\section{RESÚMENES}

Este número de Artelogie propone examinar el quehacer cultural contemporáneo de la nación caribeña a través del análisis y la reflexión innovadora propuestos por cuatro autoras, cuyos enfoques interdisciplinarios e interseccionales exploran problemáticas fluctuantes entre continuidad y ruptura, el pasado, el presente y la imaginación de posibles futuros, lo local y lo global, subjetividades y transterritorialidad en la música, la literatura y las artes visuales creadas por cubanos dentro y fuera de la isla. Las contribuciones que aquí se incluyen (junto con otros textos de interés) convidan al lector a profundizar, desde el entreverado campo cultural, en el conocimiento de las más acuciantes dinámicas que agitan la sociedad cubana, sus avatares, sus claroscuros y entresijos. Diseñan un mapa cargado de incógnitas que, en su siempre ambigua expansión-contención, surca nuevos e inexcusables desafíos a los estudios de la cambiante realidad sociocultural cubana.

Ce numéro d'Artelogie se propose d'interroger la culture contemporaine de la nation caribéenne à travers l'analyse et la réflexion proposées par les auteurs, dont les approches interdisciplinaires et intersectionnelles explorent des problèmes fluctuants entre continuité et rupture, le passé, le présent et l'imaginaire de futurs possibles. Le local et le global sont également examinés avec la transterritorialité et 
leurs subjectivités créés par les Cubains à l'intérieur et à l'extérieur de l'île, dans le domaine de la musique aussi bien que dans la littérature et les arts visuels. Les contributions présentées ici (avec d'autres textes d'intérêt) invitent le lecteur à approfondir, à partir d'un champ culturel densément imbriqué, la connaissance des dynamiques les plus pressantes qui secouent la société cubaine avec son clair-obscur et les tenants et aboutissants de ses vicissitudes.

Ces articles dessinent une cartographie chargée d'inconnus que dans son mouvement d'expansioncontraction toujours ambigu, explorent de nouveaux défis aux études de la réalité socioculturelle cubaine.

\section{ÍNDICE}

Mots-clés: Cuba, diasporas, subjectivité, transterritorialité, musique, littérature, arts visuels. Palabras claves: Cuba, diásporas, subjetividad, transterritorialidad, música, literatura, artes visuales.

\section{AUTORES}

\section{IVÁN CÉSAR MORALES FLORES}

Profesor Ayudante Doctor del Departamento de Historia del Arte y Musicología de la Universidad de Oviedo, España es desde 2015 Doctor en Musicología por la misma universidad. Es autor del libro “Identidades en proceso. Cinco compositores cubanos de la diáspora (1990-2013)", Premio de Musicología de Casa de las Américas (2016). De 2005 a 2009 fue profesor y jefe del Departamento de Musicología del Instituto Superior de Artes de La Habana. Actualmente, es miembro del Grupo de Investigación en Música Contemporánea de España y Latinoamérica Diapente XXI, la Asociación Regional para América Latina y el Caribe de la International Musicological Society, la Sociedad Española de Musicología y la red internacional de investigadores "Trayectorias: Música entre América Latina y Europa".

\section{ODETTE CASAMAYOR-CISNERO}

Profesora de literatura y cultura latinoamericanas en la Universidad de Pennsylvania. Su primer libro de ensayos, Utopía, distopía e ingravidez: reconfiguraciones cosmológicas en la narrativa postsoviética cubana (Iberoamericana-Vervuert, Madrid-Frankfurt am Main, 2013), examina, a través del análisis literario, el vacío existencial experimentado por los cubanos tras el colapso del sistema socialista de Europa del Este en los años noventa. Actualmente Odette Casamayor prepara un nuevo libro de ensayos titulado On Being Blacks: Self-identification \& Counter-Hegemonic Knowledge in Contemporary Afro-Cuban Arts. Como escritora de ficción, Odette Casamayor Cisneros ha publicado el libro de cuentos Una casa en los Catksills (primera edición: La Secta de los Perros, San Juan, Puerto Rico, 2012 y segunda edición: Letras Cubanas, La Habana, 2016). 